\title{
PROSE - Prospective Randomized Trial of the On-X Mechanical Prosthesis and the St Jude Medical Mechanical Prosthesis Evaluation (EDIT - March 21,2021\& April 16,2021)Part 1 - Preoperative Demographics and Preoperative and Operative Risk Factors
}

William Robert Eric Jamieson ( $\nabla$ wreric.jamieson@gmail.com )

Univ of British Columbia https://orcid.org/0000-0002-9611-4250

John L Ely

Clemson University

Johan Brink

Groote Schuur Hospital

Timothy Pennel

Groote Schuur Hospital

Paul Bannon

Royal Prince Alfred Hospital

Jashvant Patel

Sri Bachubahi Dayabhai Mehta Mahavir Heart Institute

Rajiv Kumar Gupta

Hero Dayanand Medical College and Hospitals

Prasanna Simha Mohan Rao

Sri Jayadeva Institute of Cardiovascular Sciences and Research

Damyanti Agrawal

Banaras Hindu University

Lar Wiklund

Sahlgrenska University

A Pieter Kappetein

Erasmus Medical Centre: Erasmus MC

Rune Haaverstad

Haukeland University Hospital: Haukeland Universitetssjukehus

Thomas Geisner

Haukeland University Hospital: Haukeland Universitetssjukehus

Torsten Doesnt 
Universitats Klinik Jena

\section{Christian Schlensak}

Universitats Klinik Tubingen

\section{Sulgunan Nair}

Apollo Hospital Chennai

\section{Craig Brown}

New Brunswick Heart Centre

\section{Matthias Siepe}

Universitats-Herzzentrum Freilbrug - Medical Center

\section{Ralph J Damiano}

Washington University School of Medicine in Saint Louis: Washington University in St Louis School of Medicine

\section{Yves Langlois}

Sir Mortimer B Davis Jewish General Hospital

\section{KM Cherian}

Lifeline Hospital

\section{Hormoz Azar}

Sentara Norfolk General Hospital

\section{John C Chen}

University of Hawaii - Kaiser-Permanente Honolulu

\section{Joseph E Bavaria}

Hospital of the University of Pennsylvania

\section{Lynn M Fedoruk}

Victoria Heart Institute Foundation

\section{Nabil A Munfakh}

Christian Hospital Northeast

\section{Sridhar}

Apollo Multispecialty Hospitals

\section{PM Scholz}

Robert Wood Johnson Medical School

\section{TA Pfeffer}

Kaiser-Permanente Los Angeles

\section{Jian Ye}

St. Paul's Hospital

\section{Research article}

Keywords: Mechanical prostheses (demographics and risk factors), Experience western world and developing world 
Posted Date: April 21st, 2021

DOI: https://doi.org/10.21203/rs.3.rs-304178/v1

License: (c) (i) This work is licensed under a Creative Commons Attribution 4.0 International License. Read Full License 


\section{Abstract}

\section{Objectives}

The PROSE trial purpose is to investigate whether the incidence of thromboembolic - related complications is reduced with a current generation mechanical prosthesis (On-X Life Technologies/CryoLife Inc. - On-X) compared with a previous generation mechanical prosthesis (St Jude Medical - SJM). The primary purpose of the initial report is to document the preoperative demographics, and the preoperative and operative risk factors by individual prosthesis and by Western and Developing populations.

\section{Methods}

The PROSE study was conducted in 29 worldwide centres and incorporated 854 subjects randomized between 2003 and 2016. The study enrollment was discontinued on August 31, 2016. The preoperative demographics incorporated age, gender, functional class, etiology, prosthetic degeneration, primary rhythm, primary valve lesion, weight, height, BSA and BMI. The preoperative and operative evaluation incorporated 24 risk factors.

\section{Results}

The total patient population (854) incorporated On-X population (461) and the St Jude Medical population (393). There was no significant difference of any of the preoperative demographics between the On-X and SJM groups. The preoperative and operative risk factors evaluation showed there was no significant difference between the On-X and St Jude Medical populations. The preoperative and operative risk factors by valve position (aortic \& mitral) also documented no differentiation.

The dominant preoperative demographics of the Western world population were older age, male gender, sinus rhythm, aortic stenosis, congenital aortic lesion, and mitral regurgitation. The dominant demographics of the Developing world population were rheumatic etiology, atrial fibrillation, aortic regurgitation, mixed aortic lesions, mitral stenosis and mixed mitral lesions. The Developing world group had only one significant risk factor, congestive heart failure. The majority of the preoperative and operative risk factors were significant in the Western world population.

\section{Conclusions}

The preoperative demographics do not differentiate the prostheses but do differentiate the Western and Developing world populations. The preoperative and operative risk factors do not differentiate the prostheses BUT do differentiate the Western and Developing world populations.

\section{Introduction}


The purpose of the PROSE (Prospective Randomized Trial of the On-X Mechanical Prosthesis and the St Jude Medical Mechanical Prosthesis Evaluation) study is to investigate whether the incidence of thromboembolic-related complications (TRC) is reduced with a current generation mechanical prosthesis (On-X Life Technologies/CryoLife Inc - On-X) compared with a previous generation mechanical prosthesis (St Jude Medical Inc - SJM). The study hypothesis was designed to access the null (H0) and alternative (HA) hypotheses.

\section{Methods}

The study design of the PROSE trial was a multi-centre, randomized trial that would sequentially enrol 400 eligible patients in each group from up to 25 participating study centres (the actual enrollment centres was 29 centres) in worldwide centres incorporating Western and Developing countries. To ensure adequate enrolment, the number of mechanical prosthesis implants performed was the key criterion in selection of these sites. It was estimated that each centre would be able to randomize a minimum of $30-$ 40 patients. In actual fact, the distribution of the patients per centre did not meet this anticipated distribution. The final analysis would begin approximately one year after the final patient was enrolled, resulting in study completion within five (5) years.

The patient eligibility of the trial included the inclusion and exclusion criteria. Patient eligibility was determined, and patient consent was obtained within seven (7) days before operation.

The inclusion criteria were:

1. The patient required an isolated mitral or isolated aortic prosthesis replacement. (Patients undergoing coronary artery bypass and/or concomitant repair of mitral or tricuspid valves were eligible).

2. The patient would be a candidate for receipt of a mechanical heart prosthesis.

3. The patient (or legal guardian) had signed a study-specific informed consent form agreeing to the randomization, data collection and follow-up requirements.

4. The patient could be having a re-operative procedure with the previous prosthesis explanted and the patient does not become a double prosthesis implantation patient.

The exclusion criteria were:

1. The patient was not a candidate to receive a mechanical heart prosthesis.

2. The patient already had a prosthetic valve other than the prosthesis (es) being replaced at the time of the study commencement.

3. The patient required a tricuspid replacement.

4. The patient was enrolled in another investigative study or trial. 
The randomization assignment of patients in the PROSE trial eliminated potential selection biases and reduced the likelihood of disproportionate distribution of both known and unknown prognostic factors between the treatment control groups. The study personnel at each site determined the randomization assignment during surgery by opening a sequentially numbered, sealed envelope for each eligible patient. Using this envelope system, patients were randomized with equal probability with one or two treatment groups, On-X mechanical prosthesis or SJM mechanical prosthesis. The random assignment of patients would be different for both aortic and mitral position. All study personnel were blinded to the randomization schedule. A randomization log containing procedural instructions and log sheets for recording randomization information were provided to each site. Any violations of the randomization assignment were communicated to the co-ordinating centre following the discovery.

The follow-up of patients occurred at discharge, 3-months, 6-months, at 1-year and annually thereafter during the conduct of the study and the longitudinal evaluation to approximately 5-years. Data collected included information regarding adverse events as defined as the "Guidelines for reporting morbidity and mortality after cardiac valvular operations" of the Society of Thoracic Surgeons and the American Association for Thoracic Surgery (STS/AATS).(1) The specific adverse events of thromboembolism and hemorrhage were specifically delineated. The thromboembolic events were delineated as reversible ischemic neurological deficit (RIND), major and thrombosis. The hemorrhagic events were all major events as defined by the guidelines inclusive of hospitalization and/or blood product transfusion as an in-patient or an outpatient. The additional follow-up included New York Heart Association (NYHA) functional classification, specific procedures and medications. The follow-up was initially conducted by telephone evaluation and contact with the attending physician as deemed necessary. If difficulty was encountered in obtaining the needed follow-up and/or complications from the information, the patient was contacted and scheduled for an office visit by the centre investigator. If this was not possible, the investigator contacted the patient's follow-up physician to obtain the required data. The patient management was conducted by the patient's attending physician, whether that be family physician, internist or cardiologist. The attending physician received notification that the patient was involved in the PROSE study along with recommendations with regard to target anticoagulation. The target anticoagulation level for aortic prostheses was INR between 2.2 and 2.8 and mitral prostheses was for 2.5 to 3.5.

The sample size for the PROSE randomized trial was dependent upon many assumptions including a projected rate of events, the measure required to detect the difference between the treatment and control groups, the selected Type I and Type II error rates and the type of significant tests used. The sample size calculation for the PROSE study assumed a rate of $1.0 \%$ per patient for major thrombotic events with the On-X prosthesis and a rate of $2.0 \%$ per patient for the St Jude Medical prosthesis based on existing literature (2-11). The sample size was calculated on the rate of late thromboembolic major events that was standardly reported in the literature or from regulatory trials for the prostheses.

It was assumed that the treatment group (On-X) would experience a $50 \%$ reduction in the incidence of major thromboembolic events relative to the SJM group. The $50 \%$ magnitude of major thromboembolic 
event reduction was considered clinically important, as well as detectable with the expected sample size. An exponential maximum likelihood test of equality of survival curves with a 0.050 one-sided significance level would have $80 \%$ power to detect the difference between a rate of 0.0100 for the On-X prosthesis and a rate of 0.0200 for the SJM prosthesis.

The data analysis will be performed with an "intent to treat" analysis. For the data analysis patients will be included in the treatment group in which they were assigned. By randomizing patients during surgery, deviations from the randomization assignment and the resulting of the dilution of the treatment effects would be minimized.

Linearized occurrence rates will be utilised to determine the performance of the prostheses with regard to the overall and major thromboembolic events and haemorrhage events. Kaplan-Meier analysis will also be utilised to evaluate the performance of the two prostheses with regard to freedom from thromboembolic events. A log-rank test will be utilised to validate the significance of the Kaplan-Meier analysis.

The true significance of the On-X mechanical prosthesis in reducing the incidence of thromboembolism is unknown. The current documented thromboembolic rates with the On-X prosthesis comes from the regulatory trials conducted for the Food \& Drug Administration of the United States, and clinical studies. (2-6) The thromboembolic rates for the St Jude Medical prosthesis are well documented in the literature from publications over the past 20 years. (7-11). Final analysis of the randomized trial will be reviewed to ascertain if the observed differences are clinically important.

The Adjudication Committee of the PROSE study consisted of the Data Safety Monitoring Board (DSMB) and the co-ordinating centre for the PROSE study at the Vancouver site. The PROSE study utilized Case Report Forms for collection of the data. Each PI monitored their centre for severe adverse events as defined by the STS/AATS guidelines. (1) The sponsor and each of the centres reported the serious adverse events (SAE) to the appropriate governments, as required by each country's law for commercially distributed products.

The PROSE study was carried out according to the principals of the Helsinki Declaration. The written, informed consent for an eligible patient was required before the patient could be included in the investigational trial. The signed consent indicated that the patient agreed to accept the random assignment of the type of prosthesis, either SJM or On-X. Each of the patients indicated that he/she would adhere to the follow-up examination schedule and completing annual data collection surveys. The signed consent form also included a statement that the study data would be made available to the sponsor (On-X Life Technologies/CryoLife Inc.). The institutional IRB (University and/or hospital) representing the prospective study site reviewed and approved the investigational plan and the prospective investigator's participation before the investigation began at the site.

The risks of valve replacement with either of these mechanical prostheses are those associated with all prosthetic replacement surgery, including thromboembolism and bleeding, which are the focus of this 
study. The outcome of adverse events typical of prosthesis replacement can be transient or permanent and including death. The risk of participating in the study was that patients (50\% of patients) could turn out to receive a prosthesis type that was associated with more thromboembolic events (blood clots) than the other prosthesis type they could have received. The study was designed to determine which prosthesis was safer. There was no specific benefit to participating in the study. The relative safety of the two prosthesis types was unknown at this time, although both prostheses are approved for commercial use by Canadian and United States governments, and all major worldwide governments. The determination of the relative safety was the reason for the study.

The patient progress and health status were carefully monitored in patients who were involved in the study, and any complications that arose were detected and treated (if necessary) at an early stage. Knowledge gained by participation in the study could be of potential benefit to other patients. The assessment of patient information gathered in the study would provide information that would assist in identifying the optimal heart prosthesis type for a patient with varied health and heart histories. It was possible that if the clinical results for one of the heart prostheses was superior, then the patient receiving that heart prosthesis could benefit from a reduction in the potential complications of mechanical prostheses. Any information identified that would be of importance to continuing participation will be disclosed in patients in a timely fashion. The alternative to participating in this study is to have valve replacement with the prosthesis of choice selected by the patient and attending cardiologist and cardiac surgeon.

\section{Results}

The total population for analysis in the PROSE trial was 854 patients implanted between 2003 and 2016. There were 939 patients screened for the trial. Of the trial patients -16 discontinued/withdrew and 84 were lost to follow-up. There was a total of 189 SUSAR (Suspected Unexpected Serious Adverse Reactions). The enrollment on the PROSE trial was completed on August 31, 2016. The follow-up for the PROSE trial will complete August 2021.

The preoperative demographics and risk factors for the total population is detailed in Tables 2 to 5 . The preoperative demographics and risk factors by aortic and mitral valve positions are detailed in the electronic tables $\mathrm{E} 1$ to $\mathrm{E} 4$.

The total population (Table 2) of the PROSE study comprised 854 patients with On-X population 461 patients and the SJM population 393 patients. Table 2 identifies specific differences between the On-X and SJM prostheses, with a gender difference that is also reflected in the lesion distribution and body surface area but not individually in height and weight. The mean age of the total population was 49.0 years with a standard deviation of 12.6 years. The gender distribution was $58.9 \%$ male. Rheumatic valve etiology was $41.5 \%$ while calcific valvular disease was $29.8 \%$. Sinus rhythm was present in $75.3 \%$ of patients and atrial fibrillation was present in $23.2 \%$ of patients. 
The preoperative demographics for Aortic Valves (E1) and Mitral Valves (E2) revealed significant differences similar to the entire population only in the aortic position between On-X and SJM prostheses. The mean age for aortic prostheses patients was $52.3+/-11.4$ years. Aortic patients were $13.7 \%$ rheumatic and $46.9 \%$ were calcific valvular disease. Of the aortic patients $92.8 \%$ were in sinus rhythm and only $5.6 \%$ were in atrial fibrillation. The mean age for mitral prostheses patients was $44.4+/-12.8$ years. Mitral patients were $81.7 \%$ rheumatic and $5.0 \%$ were calcific valvular disease. Of the mitral patients 51.1 $\%$ were in sinus rhythm and $47.7 \%$ were in atrial fibrillation.

The preoperative and operative risk factors for the total population are detailed in Table 3, while for aortic prostheses was detailed in Table E3 and for mitral prostheses was detailed in Table E4. There were no significant differences between On-X and SJM patients for all preoperative and operative risk factors.

The Western and Developing Worlds provided the most significant differences for both preoperative and operative demographics (Table 4 ) and for preoperative and operative risk factors (Table 5). The preoperative demographics revealed the patients in the developing world were younger $(43.3+/-12.6$ years versus $54.5+/-9.8<0.0001)$, predominantly female $(54.0 \%$ versus $46.0 \%<0.0001)$, predominantly rheumatic disease $(62.7 \%$ versus $7.9 \%<0.0001)$, and atrial fibrillation $(35.7 \%$ versus $10.1 \%<0.0001)$.

Aortic stenosis was more common in the western world $(66.0 \%$ versus $17.2 \%<0.0001)$ while aortic regurgitation more common in the developing world $(49.4 \%$ versus $13.9 \%<0.0001)$. (Table 4$)$. Mitral stenosis was more common in the developing world $(22.5 \%$ versus $17.2 \%<0.0001)$ while mitral regurgitation was more common in the western world $(59.9 \%$ versus $19.1 \%<0.0001)$. (Table 5$)$.

The preoperative and operative risk factors for western and developing worlds (Table 4) revealed a complete contrast for all risk factors with the significant factors predominantly in the western world. The comparative risk factors in favor of the western world population were - coronary artery disease $(29.1 \%$ versus $4.1 \%<0.0001)$, diabetes mellitus $(15.1 \%$ versus $7.4 \% 0.0004)$, hypercholesterolemia $(44.2 \%$ versus $6.5 \%<0.0001)$, preoperative creatinine ( $91.0 \%$ versus $28.5 \% 0.001$ ), hypertension ( $55.6 \%$ versus $20.4 \%$ $<0.0001)$, COPD $(14.0 \%$ versus $4.6 \%<0.0001)$, previous myocardial infarction $(8.2 \%$ versus $1.2 \%<0.0001)$, angina pectoris $(20.6 \%$ versus $6.2 \%<0.0001)$. The aortic valve percentage was more common in the western world $(87.2 \%$ versus $29.0 \%<0.0001)$. Intraoperative adverse events were more common in the western world $(12.8 \%$ versus $4.8 \%<0.0001)$. Congestive heart failure, on the other hand, was more common in the developing world $(29.3 \%$ versus $21.7 \% 0.011)$.

\section{Discussion}

Table 1 - On-X versus SJM Design Comparison 


\begin{tabular}{|l|l|l|}
\hline Feature & On-X Valve (On-X Figure 1) & SJM Valve (SJM Figure 2) \\
\hline Material & Pure pyrolytic carbon & $\begin{array}{l}\text { Silicon-alloyed pyrolytic } \\
\text { carbon }\end{array}$ \\
\hline $\begin{array}{l}\text { Sewing ring } \\
\text { position }\end{array}$ & Supraannular & Supraannular \\
\hline Valve position & Intra-supraannular & Supraannular \\
\hline $\begin{array}{l}\text { Pannus } \\
\text { overgrowth } \\
\text { protection }\end{array}$ & Yes & No \\
\hline Orifice length & $\begin{array}{l}\text { Longer natural length-to-diameter } \\
\text { ratio }\end{array}$ & $\begin{array}{l}\text { Shorter less than natural } \\
\text { length-to-diameter ratio }\end{array}$ \\
\hline Pivot design & $\begin{array}{l}\text { Actuated by remote center of } \\
\text { rotation }\end{array}$ & Fixed rotation point \\
\hline Leakage path & $\begin{array}{l}\text { Smooth through contoured pivot } \\
\text { with set gap tolerances }\end{array}$ & Jet through angular pivot \\
\hline Closing geometry & $\begin{array}{l}\text { Two points at 45ํำm leaflet tip } \\
\text { reducing closing velocity }\end{array}$ & Single point at tip of leaflet \\
\hline
\end{tabular}

\section{On-X Specific Design Features (Table 1 - Figure 1)}

As compared in Table 1 the On-X prosthesis is a pure pyrolytic carbon prosthesis with a supraannular sewing ring. The prosthesis design facilitates pannus protection (pannus protection was not a comparative feature of the PROSE trial). The long, flared orifice of the On-X prosthesis facilitates organized flow through the prosthesis (height-to-diameter ratio of about 0.6 ). The actuated pivots of the On-X prosthesis allow the leaflets to follow the blood flow through the prosthesis. The pivot purge of the On-X prosthesis facilitates the elimination of blood stasis in the prosthesis. The two-point closure of the On-X reduces the impact of leaflet closure.

\section{SJM Specific Design Features (Table 1 - Figure 2)}

The SJM prosthesis is made from a silicon-alloyed pyrolytic carbon that is less strong and more brittle than pure pyrolytic carbon. It also features a suppraannular sewing ring, but its orifice does not extend above and below the ring except at the pivot ears providing little barrier to pannus overgrowth. The height-to-diameter ratio of the housing is approximately 0.3 . Its leaflets rotate on a fixed pivot and its closing contact points are at the tips of the leaflets resulting in a higher likelihood of cavitation.

\section{Conclusion}

The completion of the long-term follow-up in six (6) residual centres in the developing world will provide the opportunity to evaluate the influence of prosthesis-type on major thromboembolism, thrombosis and major hemorrhage in accordance with the objectives of the PROSE trial. The influence of prosthesis-type in the western world and the developing world will also be evaluated for major thromboembolism, thrombosis and hemorrhage. These comparisons will be conducted by the overall population and by valve position. The PROSE study findings will afford the opportunity for comparison to the existing world literature. 


\section{Declarations}

Ethics approval and consent to participate was achieved at the institution (hospital/university) of each participating centre. The University of British Columbia, and participating hospitals - St Paul's Hospital and Vancouver General Hospital ethics committees initially approved the study.

Consent for publication was achieved by all centres having the opportunity to review the manuscript.

Availability of data and materials was provided by all participating centres as the study progressed in their centres.

Competing interests were not an issue during the progress of the study.

The funding at each of the 29 centres was the responsibility of the study sponsor (On-X Technologies/CryoLife Inc.).

The authors had the opportunity for contributions to the manuscript.

Acknowledgements

Alanna Dyck - Research Coordinator (Division of Cardiovascular Surgery - Department of Surgery, University of British Columbia) (Responsibility throughout essentially the total length of the PROSE study for the complete study).

Appreciation is provided to all research coordinators at all the study centres who provided extensive support throughout the extended length of the study.

\section{References}

1. Akins CW, Miller DC, Turina MI, Kouchoukos NT, Blackstone EH, Grunkemeier GL, et al. Guidelines for reporting mortality and morbidity after cardiac valve interventions. J Thorac Cardiovasc Surg. 2008;135:732-8.

2. On-X Valve Summary of Safety and Effectiveness. PMA P000037, May 30, 2001, and PMA P000037 S002, March 6, 2002, Food and Drug Administration.

3. Palatianos GM, Laczkovica AM, Simon P, Pomar JL, Birnbaum DE, Greve HH, et al. Multicentered European study on safety and effectiveness on the On-X prosthetic heart valve: intermediate followup. Ann Thorac Surg. 2007:83:40-6.

4. McNicholas KW, Ivey TD, Metras J, Szentpetery S, Marra SW, Masters RG, et al. North American multicenter experience with the On-X prosthetic heart valve. J Heart Valve Dis. 2006;15:73-9.

5. Laczkovics A, Heidt M, Oelert H, Laufer G, Greve H, Pomar JL, et al. Early clinical experience with the On-X prosthetic heart valve. J Heart Valve Dis. 2001;10:94-9. 
6. Chan V, Jamieson WRE, Lam B-K, Ruel M, Ling H, Fradet G, Mesana TG. Influence of the On-X mechanical prosthesis on intermediate-term major thromboembolism and hemorrhage: $\mathrm{A}$ prospective multicenter study. J Thorac Cardiovas Surg. 2010;140(5):1053-8.

7. Emery RW, Krogh C, Arom KV, Emery AM, Benyo-Albrecht K, Joyce LD, et al. The St Jude Medical Cardiac Valve Prosthesis: a 25-year experience with single valve replacement. Ann Thorac Surg. 2005;79:776-82.

8. Ikonomides JS, Krantz JM, Crumbley AJ, et al. Twenty-year experience with the St Jude Medical valve prosthesis. J Thorac Cardiovasc Surg. 2003;126:2022-31.

9. Arom KV, Emery RW, Petersen B, Radosevich DM. St Jude Medical valve prosthesis: health status of the patient after 15 years. Ann Thorac Cardiovasc Surg. 1996;2:45-9.

10. Emery RW, Arom KV, Kshettry VR, et al. Decision-making in the choice of heart valve for replacement in patients aged 60-70 years: twenty-year follow-up of the St Jude Medical aortic valve prosthesis. J Heart Valve Dis. 2001;11(Suppl 1):37-44.

11. Lund O, Nielsen SL, Arildsen H, Ilkjaer LB, Pilegaard HK. Standard aortic St Jude valve at 18 years: performance profile and determinants of outcome. Ann Thorac Surg. 2000;69:1459-65.

\section{Tables 2-5}

Table 2

Preoperative Demographics Whole Population 


\begin{tabular}{|c|c|c|c|c|}
\hline Factor & Whole Study & On-X & SJM & $\mathrm{p}$-value \\
\hline Patients (N) & 854 & 461 & 393 & $0.177^{*}$ \\
\hline Follow-up (ptyrs) & 3529.3 & 1944.2 & 1585.1 & \\
\hline Age (mean - stdev) & $49.0-12.6$ & $49.2-12.7$ & $48.9-12.4$ & 0.728 \\
\hline Gender (N - \% male) & $503-58.9$ & $287-62.3$ & $216-55.0$ & 0.026 \\
\hline \multicolumn{5}{|l|}{ NYHA (N - \%) } \\
\hline $\mathrm{I}$ & $69-8.1$ & $40-8.7$ & $29-7.4$ & 0.635 \\
\hline II & $297-34.8$ & $153-33.2$ & $144-36.6$ & \\
\hline III & $369-43.2$ & $193-41.9$ & $176-44.8$ & \\
\hline IV & $78-9.1$ & $45-9.8$ & $33-8.4$ & \\
\hline Unknown & $41-4.8$ & $30-6.5$ & $11-2.8$ & \\
\hline \multicolumn{5}{|l|}{ Etiology (N - \%) } \\
\hline Rheumatic & $343-41.5$ & $182-41.5$ & $161-41.6$ & 0.212 \\
\hline Calcific & $246-29.8$ & $132-30.1$ & $114-29.5$ & \\
\hline Prosthetic Degeneration & $20-2.4$ & $13-3.0$ & $7-1.8$ & \\
\hline Congenital & $109-13.2$ & $54-12.3$ & $55-14.2$ & \\
\hline Endocarditis & $37-4.5$ & $21-4.8$ & $16-4.1$ & \\
\hline Degenerative & $56-6.8$ & $30-6.8$ & $26-6.7$ & \\
\hline Other & $15-1.8$ & $7-1.6$ & $8-2.1$ & \\
\hline \multicolumn{5}{|l|}{ Primary Rhythm (N - \%) } \\
\hline Sinus & $628-75.3$ & $338-75.3$ & $290-75.5$ & 0.908 \\
\hline Atrial Fibrillation & $193-23.2$ & $105-23.4$ & $88-22.9$ & \\
\hline Paced & $3-0.4$ & $1-0.2$ & $2-0.5$ & \\
\hline Other & $9-1.1$ & $5-1.1$ & $4-1.0$ & \\
\hline \multicolumn{5}{|l|}{ Aortic Lesion (N - \%) } \\
\hline Stenosis & $287-50.5$ & $143-46.1$ & $144-55.8$ & 0.039 \\
\hline Regurgitation & $143-25.2$ & $79-25.4$ & $64-24.8$ & \\
\hline Mixed & $135-23.8$ & $87-28.1$ & $48-18.6$ & \\
\hline Other & $3-0.5$ & $1-0.3$ & $2-0.8$ & \\
\hline \multicolumn{5}{|l|}{ Mitral Lesion (N - \%) } \\
\hline Stenosis & $87-21.4$ & $51-23.7$ & $36-18.8$ & 0.309 \\
\hline Regurgitation & $113-27.8$ & $56-26.0$ & $57-29.7$ & \\
\hline Mixed & $205-50.4$ & $106-49.3$ & $99-51.6$ & \\
\hline Other & $2-0.5$ & $2-0.9$ & $0-0.0$ & \\
\hline Weight in kg (mean - stdev) & $73.2-22.1$ & $74.2-22.5$ & $72.0-21.6$ & 0.160 \\
\hline Height in cm (mean - stdev) & $166.5-11.2$ & $167.2-11.2$ & $165.7-11.1$ & 0.055 \\
\hline Body Surface Area in $\mathrm{m}^{2} \quad$ (mean - stdev) & $1.80-0.29$ & $1.82-0.29$ & $1.78-0.28$ & 0.042 \\
\hline Body Mass Index in kg/m² (mean - stdev) & $26.2-7.0$ & $26.3-7.2$ & $26.0-6.7$ & 0.531 \\
\hline
\end{tabular}

* Test for randomization across whole trial includes an adjustment from $\mathrm{p}=0.5$, because the Australian cohort was randomized 2:1 not 1:1 arriving at $\mathrm{p}=0.48$ for the trial.

Table 3

Preoperative and Operative Risk Factors Whole Study 


\begin{tabular}{|c|c|c|c|c|}
\hline Factor & Whole Study & On-X & SJM & p-value \\
\hline Smoker (N - \%) & $302-35.4$ & $170-36.9$ & $132-33.6$ & 0.316 \\
\hline Coronary Disease in Family (N - \%) & $144-16.9$ & $78-16.9$ & $66-16.8$ & 0.960 \\
\hline Diabetes (N - \%) & $97-11.4$ & $51-11.1$ & $46-11.7$ & 0.769 \\
\hline High Cholesterol (N - \%) & $220-25.8$ & $129-28.0$ & $91-23.2$ & 0.108 \\
\hline Preoperative Creatinine (mean - SD) & $89.8-65.2$ & $91.7-71.7$ & $87.6-56.8$ & 0.377 \\
\hline Renal Failure (N -\%) & $35-4.1$ & $18-3.9$ & $17-4.3$ & 0.752 \\
\hline Hypertension (N - \%) & $328-38.4$ & $175-38.0$ & $153-38.9$ & 0.772 \\
\hline History of CVA (N - \%) & $45-5.3$ & $26-5.6$ & $19-4.8$ & 0.598 \\
\hline Previous Endocarditis (N - \%) & $37-4.3$ & $23-5.0$ & $14-3.6$ & 0.306 \\
\hline Existing COPD (N - \%) & $80-9.4$ & $44-9.5$ & $36-9.2$ & 0.849 \\
\hline Immunosuppressed (N - \%) & $13-1.5$ & $8-1.7$ & $5-1.3$ & 0.576 \\
\hline Peripheral Vascular Disease (N - \%) & $23-2.7$ & $16-3.5$ & $7-1.8$ & 0.128 \\
\hline Carotid Vascular Disease (N - \%) & $45-5.3$ & $23-5.0$ & $22-5.6$ & 0.691 \\
\hline Previous Cardiac Surgery (N - \%) & $125-14.6$ & $66-14.3$ & $59-15.0$ & 0.776 \\
\hline Previous MI (N - \%) & $41-4.8$ & $24-5.2$ & $17-4.3$ & 0.549 \\
\hline Congestive Heart Failure (N - \%) & $217-25.4$ & $124-26.9$ & $93-23.7$ & 0.297 \\
\hline Angina (N - \%) & $116-13.6$ & $60-13.0$ & $56-14.2$ & 0.601 \\
\hline Cardiogenic Shock (n - \%) & $4-0.5$ & $3-6.5$ & $1-0.3$ & 0.392 \\
\hline Resuscitation (N - \%) & $5-0.6$ & $3-6.5$ & $2-0.5$ & 0.789 \\
\hline Ejection Fraction \% (mean - SD) & $55.5-11.5$ & $55.2-11.5$ & $55.9-11.5$ & 0.365 \\
\hline Preoperative Status (N - \%) & & & & \\
\hline Elective & $742-86.9$ & $401-87.0$ & $339-86.3$ & 0.738 \\
\hline Urgent & $106-12.4$ & $57-12.4$ & $51-13.0$ & \\
\hline Emergent & $6-0.7$ & $3-0.7$ & $3-0.7$ & \\
\hline Concomitant Procedures (N - \%) & $286-33.5$ & $152-33.0$ & $134-34.1$ & 0.727 \\
\hline Intraoperative AE's (N - \%) & $76-8.9$ & $42-9.1$ & $34-8.7$ & 0.814 \\
\hline
\end{tabular}

Table 4

Preoperative Demographics for Western versus Developing World 


\begin{tabular}{|c|c|c|c|c|}
\hline Factor & Whole Study & Western & Developing & p-value \\
\hline Patients $(\mathrm{N})$ & 854 & 437 & 417 & \\
\hline Follow-up (ptyrs) & 3529.3 & 2213.9 & 1315.4 & \\
\hline Age (mean - stdev) & $49.0-12.6$ & $54.5-9.8$ & $43.3-12.6$ & $<0.0001$ \\
\hline Gender (N - \% male) & $503-58.9$ & $311-71.2$ & $192-46.0$ & $<0.0001$ \\
\hline \multicolumn{5}{|l|}{ NYHA $(\mathrm{N}-\%)$} \\
\hline $\mathrm{I}$ & $69-8.1$ & $64-14.6$ & $5-1.2$ & $<0.0001$ \\
\hline II & $297-34.8$ & $154-35.2$ & $143-34.3$ & \\
\hline III & $369-43.2$ & $152-34.8$ & $217-52.0$ & \\
\hline IV & $78-9.1$ & $48-11.0$ & $30-7.2$ & \\
\hline Unknown & $41-4.8$ & $19-4.4$ & $22-5.3$ & \\
\hline \multicolumn{5}{|l|}{ Etiology (N - \%) } \\
\hline Rheumatic & $343-41.5$ & $30-7.9$ & $313-62.7$ & $<0.0001$ \\
\hline Calcific & $246-29.8$ & $194-51.2$ & $58-11.6$ & \\
\hline Prosthetic Degeneration & $20-2.4$ & $6-1.6$ & $14-2.8$ & \\
\hline Congenital & $109-13.2$ & $92-24.3$ & $51-10.2$ & \\
\hline Endocarditis & $37-4.5$ & $16-4.2$ & $27-5.4$ & \\
\hline Degenerative & $56-6.8$ & $35-9.2$ & $25-5.0$ & \\
\hline Other & $15-1.8$ & $6-1.6$ & $11-2.2$ & \\
\hline \multicolumn{5}{|l|}{ Primary Rhythm (N - \%) } \\
\hline Sinus & $626-75.3$ & $366-83.8$ & $262-62.8$ & $<0.0001$ \\
\hline Atrial Fibrillation & $193-23.2$ & $44-10.1$ & $149-35.7$ & \\
\hline Paced & $3-0.4$ & $1-0.2$ & $2-4.8$ & \\
\hline Other & $9-1.1$ & $5-1.1$ & $4-9.6$ & \\
\hline \multicolumn{5}{|l|}{ Aortic Lesion (N - \%) } \\
\hline Stenosis & $287-50.5$ & $256-66.0$ & $31-17.2$ & $<0.0001$ \\
\hline Regurgitation & $143-25.2$ & $54-13.9$ & $89-49.4$ & \\
\hline Mixed & $135-23.8$ & $77-19.8$ & $58-32.2$ & \\
\hline Other & $3-0.5$ & $1-0.3$ & $2-1.1$ & \\
\hline \multicolumn{5}{|l|}{ Mitral Lesion (N - \%) } \\
\hline Stenosis & $87-21.4$ & $15-17.2$ & $72-22.5$ & $<0.0001$ \\
\hline Regurgitation & $113-27.8$ & $52-59.8$ & $61-19.1$ & \\
\hline Mixed & $205-50.4$ & $20-23.0$ & $185-57.8$ & \\
\hline Other & $2-0.5$ & $0-0.0$ & $2-0.6$ & \\
\hline Weight in kg (mean - stdev) & $73.2-22.1$ & $86.0-19.8$ & $60.4-16.1$ & $<0.0001$ \\
\hline Height in cm (mean - stdev) & $166.5-11.2$ & $172.1-9.7$ & $161.0-9.7$ & $<0.0001$ \\
\hline Body Surface Area in $\mathrm{m}^{2} \quad$ (mean - stdev) & $1.80-0.29$ & $1.98-0.23$ & $1.62-0.21$ & $<0.0001$ \\
\hline Body Mass Index in $\mathrm{kg} / \mathrm{m}^{2}$ (mean - stdev) & $26.2-7.0$ & $29.1-6.6$ & $23.3-6.1$ & $<0.0001$ \\
\hline
\end{tabular}

Table 5

Preoperative and Operative Risk Factors for Western versus Developing Worlds 


\begin{tabular}{|c|c|c|c|c|}
\hline Factor & Whole Study & Western & Developing & p-value \\
\hline Smoker (N - \%) & $302-35.4$ & $231-52.9$ & $71-17.0$ & $<0.0001$ \\
\hline Coronary Disease in Family ( $\mathrm{N}$ - \%) & $144-16.9$ & $127-29.1$ & $17-4.1$ & $<0.0001$ \\
\hline Diabetes $(\mathrm{N}-\%)$ & $97-11.4$ & $66-15.1$ & $31-7.4$ & 0.0004 \\
\hline High Cholesterol (N - \%) & $220-25.8$ & $193-44.2$ & $27-6.5$ & $<0.0001$ \\
\hline Preoperative Creatinine (mean - SD) & $89.8-65.2$ & $98.1-91.0$ & $82.9-28.5$ & 0.001 \\
\hline Renal Failure (N -\%) & $35-4.1$ & $19-4.3$ & $16-3.8$ & 0.711 \\
\hline Hypertension (N - \%) & $328-38.4$ & $243-55.6$ & $85-20.4$ & $<0.0001$ \\
\hline History of CVA $(\mathrm{N}-\%)$ & $45-5.3$ & $24-5.5$ & $21-5.0$ & 0.744 \\
\hline Previous Endocarditis (N - \%) & $37-4.3$ & $19-4.3$ & $18-4.3$ & 0.989 \\
\hline Existing COPD (N - \%) & $80-9.4$ & $61-14.0$ & $19-4.6$ & $<0.0001$ \\
\hline Immunosuppressed (N - \%) & $13-1.5$ & $12-2.7$ & $1-0.2$ & 0.003 \\
\hline Peripheral Vascular Disease (N - \%) & $23-2.7$ & $18-4.1$ & $5-1.2$ & 0.009 \\
\hline Carotid Vascular Disease (N - \%) & $45-5.3$ & $26-5.9$ & $19-4.6$ & 0.395 \\
\hline Previous Cardiac Surgery (N - \%) & $125-14.6$ & $54-12.4$ & $71-17.0$ & 0.058 \\
\hline Previous MI (N - \%) & $41-4.8$ & $36-8.2$ & $5-1.2$ & $<0.0001$ \\
\hline Congestive Heart Failure (N - \%) & $217-25.4$ & $95-21.7$ & $122-29.3$ & 0.011 \\
\hline Angina (N - \%) & $116-13.6$ & $90-20.6$ & $26-6.2$ & $<0.0001$ \\
\hline Cardiogenic Shock (n - \%) & $4-0.5$ & $1-0.2$ & $3-0.7$ & 0.295 \\
\hline Resuscitation (N - \%) & $5-0.6$ & $2-0.5$ & $3-0.7$ & 0.619 \\
\hline Ejection Fraction \% (mean - SD) & $55.5-11.5$ & $56.3-12.9$ & $54.9-10.2$ & 0.080 \\
\hline \multicolumn{5}{|l|}{ Preoperative Status (N - \%) } \\
\hline Elective & $742-86.9$ & $393-89.9$ & $349-83.7$ & 0.023 \\
\hline Urgent & $106-12.4$ & $41-9.4$ & $65-15.6$ & \\
\hline Emergent & $6-0.7$ & $3-0.7$ & $3-0.7$ & \\
\hline Aortic Valve Percentage & $502-58.8$ & $381-87.2$ & $121-29.0$ & $<0.0001$ \\
\hline Concomitant Procedures (N - \%) & $286-33.5$ & $133-30.4$ & $153-36.7$ & 0.051 \\
\hline Intraoperative AE’s (N - \%) & $76-8.9$ & $56-12.8$ & $20-4.8$ & $<0.0001$ \\
\hline
\end{tabular}

\section{Figures}

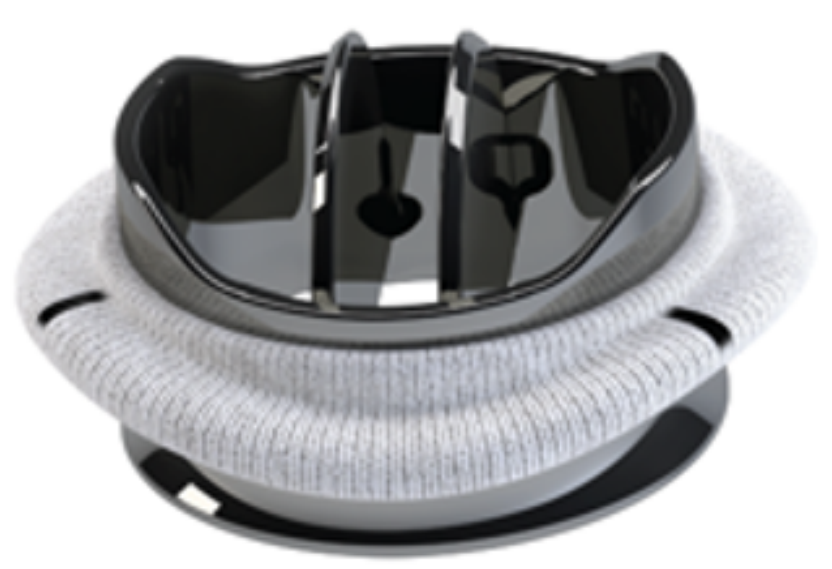

Figure 1 


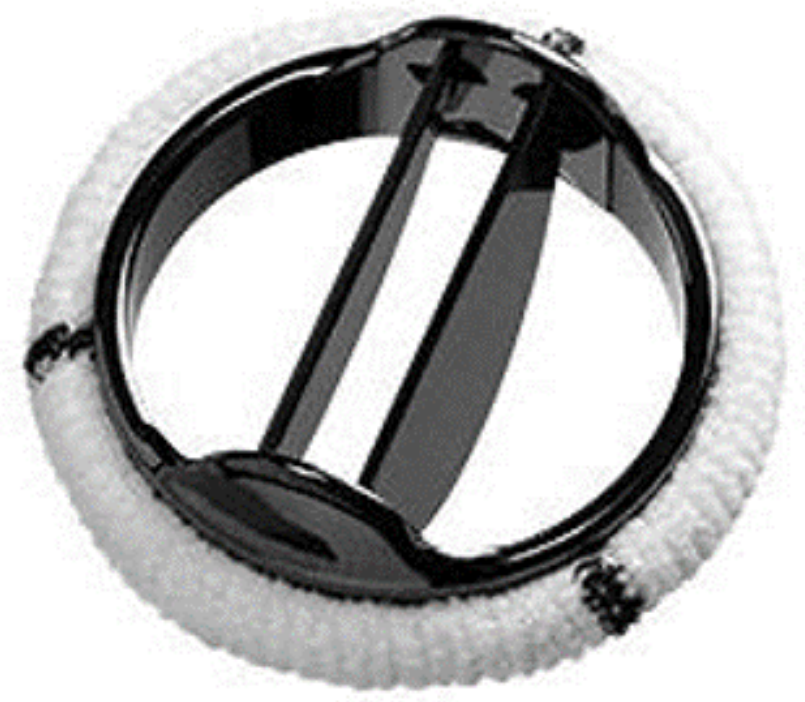

Figure 2

SJM Aortic Valve

\section{Supplementary Files}

This is a list of supplementary files associated with this preprint. Click to download.

- ExtendedDataTables.docx 